\title{
The prevalence of intestinal parasites in hemodialysis patients in Bushehr, Iran
}

\author{
Afshin BARAZESH, ${ }^{1,2}$ Moradali FOULADVAND, ${ }^{1}$ Rahim TAHMASEBI, ${ }^{3}$ Ali HEYDARI, ${ }^{2}$ \\ Jamal FALLAHI ${ }^{4}$ \\ 'The Persian Gulf Marine Biotechnology Research Center, Bushehr University of Medical Sciences, \\ Bushehr, Iran; 'Department of Parasitology and Mycology, School of Medicine, Shiraz University of \\ Medical Sciences, Shiraz, Iran; ${ }^{3}$ Department of Statistics, Faculty of Health and Nutrition, Bushehr \\ University of Medical Sciences, Bushehr, Iran; ${ }^{4}$ Department of Microbiology and Virology, Faculty of \\ Medicine, Mashhad University of Medical Sciences, Mashhad, Iran
}

\begin{abstract}
Hemodialysis patients, due to a dysfunction of the immune response, are prone to a variety of opportunistic infections. Studies of intestinal parasitic infections in these patients are limited. Therefore, the present study was performed to determine the prevalence of these infections in patients on hemodialysis in Bushehr. In this cross-sectional study, fecal samples have been collected from all hemodialysis patients who were continuously referred from September 2011 to September 2012 to the dialysis center at Bushehr and tested using routine parasitological methods. From a total of 88 patients studied, 25 patients (28.4\%) were infected with one or more intestinal parasites. Blastocystis hominis and Entamoeba coli with $13.6 \%$ and $6.7 \%$ prevalence had the highest prevalence among the patients, respectively. The age group 51-70 years had the highest rates of infection. Statistical analysis showed no relationship between sex and the risk of intestinal parasites. Seventeen percent of infected patients showed up with diarrhea and this relationship was statistically significant. Considering the high prevalence of intestinal parasitic infection among hemodialysis patients in Bushehr and also the high probability of infection in these patients, it is recommended that periodic examinations and screening patients during dialysis and before kidney transplantation should be a part of routine medical care.
\end{abstract}

Key words: Intestinal parasites, hemodialysis, Bushehr, Iran

\section{INTRODUCTION}

Despite continuous efforts and programs organized by the World Health Organization (WHO), parasitic infections are one of the obstacles to economic and social development and a major health problem in most countries of the world, particularly in developing countries. ${ }^{1,2}$

Correspondence to: A. Barazesh, Ph.D Student, Department of Microbiology and Parasitology, Faculty of Medicine, Bushehr University of Medical Sciences, P. O. Box 3631, Moallem Street, Bushehr 7518759577, Iran. E-mail: afshin914@gmail.com
According to the statistics published by the WHO, about 3 billion people worldwide are infected with parasitic infections. ${ }^{3}$ Although it is expected that because of the high economic and health conditions in developed countries, these infections are not much of importance, but with the daily increase in the number of patients with immune deficiency, increase organ transplant surgery and chemical and immune-suppressing drugs and radiation therapy, high statistics related to parasitic infection is not unlikely. ${ }^{4,5}$

Compared with healthy people, patients with immune suppressed systems are more vulnerable for parasitic infections. Among these patients, a large group of organ 
transplant recipients, patients taking corticosteroid drugs and chemotherapy, patients with cancer, acquired immune deficiency syndrome (AIDS) patients, and people undergoing radiation therapy as well as patients undergoing hemodialysis can be pointed. ${ }^{6,7}$ With more than $95 \%$ of kidney damage, accumulation of toxins in the body is increased sufficiently and sustaining life would not be possible without the use of dialysis or kidney transplant. ${ }^{8}$ Several reports indicate that populations with renal dysfunction requiring dialysis are rising. ${ }^{9}$ The number of hemodialysis patients has doubled since $1990 .{ }^{9}$ According to America's renal information, approximately 90\% of patients with chronic renal failure are on hemodialysis. ${ }^{10}$ The number of patients with kidney complications is increasing significantly time by time. For instance, the number of those patients increased from 14000 in 2007 to 22000 in 2010.9.10

Patients with chronic renal failure who are undergoing hemodialysis because of dysfunction and decreased lymphocytes, dysfunction of the complement system and immune responses, including chemotaxis and phagocytosis, have a high probability of suffering from a variety of opportunistic viral and parasitic infections. ${ }^{11-13}$ In a study in hemodialysis patients in Isfahan, Iran, the prevalence of intestinal parasitic infections was at 23.9\%; the highest infection rate was in persons 51-65 years old with 29.7\% incidence. There was a significant relationship between prevalence and age, duration of dialysis, and health status of people in that study. ${ }^{5}$

Considering that the prevalence of intestinal parasitic infections has a high percentage in dialysis patients, it is necessary that doctors and nephrologists should clinically test these patients for intestinal parasitic infections before medication drugs. However, in patients with immune deficiency, due to a decrease in white blood cells, common signs and symptoms of infection such as fever withheld and diagnosis of infection in these patients is difficult; therefore, it seems that identification of parasitic infections relying on special parasitology methods is necessary in these groups. ${ }^{14}$ Given that few studies have been performed in this regard in Iran, the present study was conducted to determine the prevalence of intestinal parasitic infections in hemodialysis patients in southwest of Iran, Bushehr.

\section{MATERIALS AND METHODS}

This study was confirmed by Bushehr University of Medical Sciences with ethic number: 20.71.7170.

In this cross-sectional study, all the hemodialysis patients in Bushehr were studies because there is just one center for those patients in Bushehr and we had access to all of them in period of September 2011 till September 2012.

After getting permission to conduct research and coordination between the authorities, records were lookup at the hospital dialysis center and through interviews and questionnaires were completed. Questionnaire was designed on demographic information as well as important factors and variables involved in this study. Stool sample container was delivered to each of the subjects. The next day the samples were collected in standard condition transferred to the parasitology laboratory at Bushehr University of Medical Sciences. All samples were tested using direct smear (wet mount and lugol) and, also, to increase the accuracy of the test, the formalin-ether concentration method were used according to the protocol recommended by the WHO. Test results with data from the questionnaires were analyzed using SPSS software version 18 (SPSS Inc., Chicago, IL, USA; version 18).

\section{RESULTS}

In this cross-sectional study, all patients undergoing hemodialysis in Bushehr, Iran, were studied for a year. From a total of 88 patients studied, 25 patients (28.4\%) were infected with one or more intestinal parasites. Blastocystis hominis with $13.6 \%$ and then Entamoeba coli with $6.7 \%$ prevalence had the highest prevalence among the patients, respectively. Of the total cases, 21 cases (23.9\%) were infected with only one species of parasite and four people (4.5\%) with more than one parasite species. Results of the prevalence of intestinal parasites in hemodialysis patients are given in Table 1 according to the type of parasites.

Table 2 shows the prevalence of intestinal parasites by age and, as implied, the age group $51-70$ years had the

Table 1 Distribution of intestinal parasites in hemodialysis patients in Bushehr

\begin{tabular}{lcc}
\hline Parasite & Frequency & Percentage \\
\hline Blastocystis hominis & 8 & 9 \\
Entamoeba coli & 6 & 6.7 \\
Giardia lamblia & 3 & 3.4 \\
Endolimax nana & 2 & 2.3 \\
Iodamoeba bütchlii & 1 & 1.2 \\
Taenia saginata & 1 & 1.2 \\
Mixed infection & 4 & 4.6 \\
Noninfection & 63 & 71.6 \\
Total & 88 & 100 \\
\hline
\end{tabular}


Table 2 Distribution of intestinal parasites in hemodialysis patients by age

\begin{tabular}{|c|c|c|c|c|c|c|}
\hline \multirow[b]{3}{*}{ Age } & \multicolumn{4}{|c|}{ Result } & \multirow{3}{*}{\multicolumn{2}{|c|}{ Total }} \\
\hline & \multicolumn{2}{|c|}{ Negative } & \multicolumn{2}{|c|}{ Positive } & & \\
\hline & $\mathrm{N}$ & $\%$ & $\mathrm{~N}$ & $\%$ & & \\
\hline$\leq 30$ & 12 & 13.6 & 1 & 1.1 & 13 & 14.8 \\
\hline $31-50$ & 16 & 18.2 & 7 & 8 & 23 & 26.1 \\
\hline $51-70$ & 25 & 28.4 & 14 & 15.9 & 39 & 44.3 \\
\hline$>71$ & 10 & 11.4 & 3 & 3.4 & 13 & 14.8 \\
\hline Total & 63 & 71.6 & 25 & 28.4 & 88 & 100 \\
\hline
\end{tabular}

highest rates of infection. However, no significant correlation was found between the incidence of intestinal parasites and age (Table 2).

Forty-six of the patients (52.3\%) were male and others $(47.7 \%)$ were female. Statistical analysis showed no relationship between sex and the risk of infection with intestinal parasites. In Table 3, the prevalence of intestinal parasites in hemodialysis patients is noted by sex.

Sixty-three of the patients studied (71.6\%) were urban dwellers and 25 patients (28.4\%) were from rural areas. In terms of education levels, patients were divided into three groups: no education (45.5\%), low education (36.4\%) and secondary education (18.2\%). Some other variables such as job, history of contact with animals, clinical symptoms as abdominal pain, appetite, nausea, vomiting, diarrhea and weight loss, and allergies were also analyzed. The tests revealed no significant differences between parasitic infection and abdominal pain, although a significant number of hemodialysis patients infected with intestinal parasites also had abdominal pain at the same time in comparison with those who were not infected ( $P$ value $=0.05$ ). Also, $17 \%$ of infected patients have diarrhea and this association was statistically significant $(\mathrm{P}$ value $<0.03$ ) (Table 4).

\section{DISCUSSION}

Immunocompromised patients are more vulnerable to parasitic infections. ${ }^{5}$ Patients with chronic renal failure

Table 3 Distribution of intestinal parasites in hemodialysis patients by sex

\begin{tabular}{|c|c|c|c|c|c|c|}
\hline \multirow[b]{3}{*}{ Sex } & \multicolumn{4}{|c|}{ Result } & & \\
\hline & \multicolumn{2}{|c|}{ Negative } & \multicolumn{2}{|c|}{ Positive } & \multicolumn{2}{|c|}{ Total } \\
\hline & $\mathrm{N}$ & $\%$ & $\mathrm{~N}$ & $\%$ & $\mathrm{~N}$ & $\%$ \\
\hline Male & 32 & 36.4 & 14 & 15.9 & 46 & 52.3 \\
\hline Female & 31 & 35.2 & 11 & 12.5 & 42 & 47.7 \\
\hline Total & 63 & 71.6 & 25 & 28.4 & 88 & 100 \\
\hline
\end{tabular}

Table 4 Distribution of intestinal parasites in hemodialysis patients by some effective factors

\begin{tabular}{|c|c|c|c|c|c|}
\hline \multirow[b]{3}{*}{ Variables } & \multicolumn{4}{|c|}{ Prevalence } & \multirow[b]{3}{*}{$\mathrm{P}$ value } \\
\hline & \multicolumn{2}{|c|}{ Positive } & \multicolumn{2}{|c|}{ Negative } & \\
\hline & $\mathrm{n}$ & $\%$ & $\mathrm{n}$ & $\%$ & \\
\hline \multicolumn{6}{|l|}{ Residence } \\
\hline City & 17 & 19.3 & 46 & 52.3 & 0.42 \\
\hline Village & 8 & 9.1 & 17 & 19.3 & \\
\hline \multicolumn{6}{|l|}{ Education level } \\
\hline Illiterate & 15 & 17 & 25 & 28.4 & \\
\hline Low literacy & 7 & 8 & 25 & 28.4 & 0.10 \\
\hline Educated & 3 & 3.4 & 13 & 14.8 & \\
\hline \multicolumn{6}{|c|}{ Abdominal pain } \\
\hline Yes & 12 & 13.6 & 17 & 19.3 & 0.05 \\
\hline No & 13 & 14.8 & 46 & 52.3 & \\
\hline \multicolumn{6}{|l|}{ Appetite } \\
\hline Yes & 5 & 5.7 & 21 & 24.1 & 0.16 \\
\hline No & 19 & 21.8 & 42 & 48.3 & \\
\hline \multicolumn{6}{|l|}{ Nausea } \\
\hline Yes & 12 & 13.8 & 29 & 33.3 & 0.60 \\
\hline No & 12 & 13.8 & 34 & 39.1 & \\
\hline \multicolumn{6}{|l|}{ Diarrhea } \\
\hline Yes & 15 & 17 & 19 & 21.6 & $<0.03$ \\
\hline No & 10 & 11.4 & 44 & 50 & \\
\hline \multicolumn{6}{|l|}{$\begin{array}{l}\text { No } \\
\text { Lose weight }\end{array}$} \\
\hline Yes & 12 & 13.6 & 22 & 25 & 0.18 \\
\hline No & 13 & 14.8 & 41 & 46.6 & \\
\hline \multicolumn{6}{|l|}{ Itch } \\
\hline Yes & 9 & 10.3 & 32 & 36.8 & 0.19 \\
\hline No & 15 & 17.2 & 31 & 35.6 & \\
\hline
\end{tabular}

who are on hemodialysis, resulting in dysfunction of the immune response, are also prone to a variety of opportunistic infections. ${ }^{5,11}$ Many studies have been conducted on the prevalence of intestinal parasitic infections in immunocompromised patients, especially in AIDS patients; however, in patients who are undergoing dialysis regularly because of chronic kidney failure, these studies are limited. ${ }^{15-17}$ In these patients the typical non-specific symptoms, such as fever might not be seen due to the decreased number of white blood cells. Therefore, diagnosis can be difficult; therefore, performing conventional parasitological methods to detect the parasitic infections in this group of patients are crucial. ${ }^{14}$ In the present study, the prevalence of intestinal parasites was achieved at $28.4 \%$ which is rather remarkable and, because of the specific population, has potential importance. This result has similarity with some studies carried out in other places; in a study conducted in dialysis patients in Isfahan in 2008, the incidence was reported at $23.9 \%$, the 
researcher has suggested clinical tests for these patients before prescribing medicine and also pretransplant as a care program. ${ }^{5}$ In another study in 2000 that was conducted on cancer patients receiving chemotherapy, 34\% of them were infected with intestinal parasites and fecal specific tests is mentioned as the basic measures to reduce such infections before starting and during chemotherapy. ${ }^{18}$ The reported prevalence of intestinal parasites in immunosuppressed patients in Tehran, which was performed in 1998, was at 34.5\%. ${ }^{4}$ Some studies have reported a higher and lower prevalence than in this study; in a study on dialysis patients, $45.1 \%$ of them were infected with various types of intestinal parasites, the authors suggest that routine parasitology tests should be included in these groups. ${ }^{19}$ On the other hand, some studies have reported a lower incidence than expected; in a study in patients with malignancy in Hamedan, 16\% prevalence was achieved and the main reason for the low incidence in these patients compared with its prevalence in the region is expressed because of the effects of the drugs used in chemotherapy. ${ }^{20}$ It seems that observed differences in outcomes are due to differences in study population, study duration, climatic conditions, customs, and culture and dietary habits.

In the present study, B. hominis was the most common intestinal parasite as an opportunistic pathogen and it was also the same parasite reported as most common in some other studies on dialysis or immunosuppressed patients. ${ }^{4,18,19,21}$ Blastocystis hominis is an opportunistic parasite and according to many researchers' recommendations, if the infection is accompanied with clinical symptoms and these symptoms cannot be explained by other factors, it seems medical therapy is necessary in these cases. ${ }^{4,18}$ In this review, E. coli was identified as the second most common parasite with $6.7 \%$ prevalence. Although E. coli is a nonpathogenic parasite, however, the high prevalence of this parasite is important as an indicator for poor health, especially in terms of water and food contamination that should be considered. ${ }^{22}$ In this study, Giardia lamblia is a third common parasite. This parasite is a pathogen and it can be the cause of many gastrointestinal disorders and dyspepsia. ${ }^{23}$ Two nonpathogenic protozoan Endolimax nana and Iodamoeba bütchlii are the next in ranks and as E. coli indicate the lack of proper health standards. In this research, protozoan infection rate was much higher than helminthes and the only worm infection reported is Taenia saginata. Undoubtedly, some health appropriate measures, such as not using human feces as fertilizer on farms, and health education can be logical justification for reducing the types of worm infections and recent statistics indicate this fact. Although in the present study, statistical analysis did not show a significant relationship between infection with level of education, age, and sex, infection rate in the age group 51-70 years was higher than other age groups. In some similar studies, the highest prevalence was reported in the age group above 50 years. ${ }^{5,18,20}$ In a study, infection rates in urban areas is mentioned higher than in rural areas and the author has described that it is because population is higher in urban areas compared with rural areas. ${ }^{5}$ In the present study, there was no relationship between the prevalence of infection and residence.

Another variable evaluated in this study includes the relationship between infection and gastrointestinal symptoms, such as some abdominal pain, nausea, diarrhea, appetite, weight loss, and pruritus. Statistical analysis showed that there was a significant relationship between the infection and diarrhea. In a similar study, the highest prevalence of infection was detected in patients with diarrhea, but this relationship was not significant. ${ }^{5}$ Of the limitations of this study, the absence of a control group with the experimental group can be noted, which was not possible because of financial restrictions, and it seems that this issue could be due to the lack of significant relationship between infection and some symptoms.

Considering the high prevalence of intestinal parasitic infection among hemodialysis patients in Bushehr, Iran, and also considering the fact that the immune system of these patients has less efficiency to deal with opportunistic infections compared with healthy subjects, it is recommended that periodic examinations and screening patients during dialysis and before kidney transplantation should be a part of routine medical care.

\section{ACKNOWLEDGMENT}

The authors are grateful to the Vice-chancellor of Research of Bushehr University of Medical Sciences for the financial support. This study was granted by Bushehr University of Medical Sciences with grant number: 4435.

Manuscript received April 2014; revised December 2014.

\section{REFERENCES}

1 Undonsi J, Behnke J, Gillbert F. Analysis of the prevalence of infection and association between human gastrointestinal nematodes among different age classes living in the urban and suburban communities of port Harcourt, Nigeria. J Helminthol. 1996; 70:75-84. 
2 Barazesh A, Hazrati Tape K, Mohammadzade H, Khashave S. The study of prevalence of intestinal parasitic infections in the personnel of private and governmental rehabilitation centers of Urmia. J Urmia Nur Mid Fac. 2007; 5:100-104.

3 Kousha A, Hakimi S, Fallah E, Nokhahi I, Sarafraz S, Shahnami A. Prevalence of Intestinal Parasites among Symptomless Primary School Children Attending Urban Health Centers, Tabriz. Med J Tabriz Uni Med Sci. 2011; 33:58-62.

4 Athari A, Sadafi H, Tokeh GR. Intestinal parasites in immunocompromised patients in Tehran in 1998. J Zanjan Uni Med Sci. 2000; 30:61-68.

5 Emami Naiini A, Shokrian A, Shahrzad S, Aazami M, Hejazi SH, Tazhibi M. The prevalence of intestinal parasitic and fungal agents in hemodialysis patients in Isfahan. J Isfahan Med Sch. 2011; 121:1655-1667.

6 Antonio A, Jose I. Diarrheal diseases in the immunocompromised host. Pediatr Infect Dis J. 1984; 6:894906.

7 Azami M, Sharifi M, Hejazi SH, Tazhibi M. Intestinal parasitic infections in renal transplant recipients. Braz J Infect Dis. 2010; 14:15-18.

8 Tayyebi A, Salimi SH, Mahmoudi H, Tadrisi SD. Comparison of quality of life in haemodialysis and renal transplantation patients. Iran J Critic Care Nur. 2010; 3:7-8.

9 Mahmody S, Salhnegad G, Nazaryan S, Yaghobi M. A comparison study of depression between hemodialysis patients and renal transplant recipients. Iran J Nur Res. 2010; 5:73-80.

10 Sajjadi A, Farmahini Farahani B, Esmailpoor Zanjani S, Dormanesh B, Zare M. Effective factors on fatigue in patients with chronic renal failure undergoing hemodialysis. Iran J Critic Care Nur. 2010; 3:13-14.

11 Botero JH, Castano A, Montoya MN, Ocampo NE, Hurtado MI, Lopera MM. A preliminary study of the prevalence of intestinal parasites in immunocompromised patients with and without gastrointestinal manifestations. Rev Inst Med Trop Sao Paulo. 2003; 45:197-200.
12 Hayashi M, Inamori M, Goto K, et al. Blastocystis hominis infection in patient with regular dialysis. J Gastroenterol. 2006; 41:605-606.

13 Lewthwaite P, Gill GV, Hart CA, Beeching NJ. Gastrointestinal parasites in the immunocompromised. Curr Opin Infect Dis. 2005; 18:427-435.

14 Brayman KL, Stephanian E, Matas AJ, et al. Analysis of infectious complications occurring after solid-organ transplantation. Arc Surg. 1992; 127:38-48.

15 Kumar SS, Ananthan S, Saravanan P. Role of coccidian parasites in causation of diarrhoea in HIV infected patients in Chennai. Indian J Med Res. 2002; 116:85-89.

16 Prasad KN, Nag VL, Dhole TN, Ayyagari A. Identification of enteric pathogens in HIV-positive patients with diarrhoea in northern India. J Health Popul Nutr. 2000; 18:23-26.

17 Seyrafian S, Pestehchian N, Kerdegari M, Yousefi HA, Bastani B. Prevalence rate of Cryptosporidium infection in hemodialysis patients in Iran. Hemodial Int. 2006; 10:375-379.

18 Togeh GR, Keyhani M, Atharei A, Sadafei H. Prevalence of intestinal parasites in cancer patients undergoing chemotherapy. Tehran Uni Med J. 2000; 58:52-58.

19 Kulik RA, Morais Falavigna DL, Nishi L, Araujo SM. Blastocystis sp. and other intestinal parasites in hemodialysis patients. Braz J Infect Dis. 2008; 12:338-341.

20 Monsef A, Hashemi SH, Abbasi M, Taherkhani H, Shalchi Z, Eliasi A. Frequency of intestinal parasites in patients with malignancy, admitted in oncology ward of Sina Hospital, Hamadan, Iran. J GorganUni Med Sci. 2008; 9:51-55.

21 Nateghi Rostami M, Keshavarz H, Eskandari E, Kia EB, Rezaeian M. Intestinal parasitic infections in renal transplant recipients. Iran J Parasitol. 2007; 2:16-23.

22 Fouladvand M, Barazesh A, Tahmasebi R. Prevalence of intestinal parasites among workers involved in collection, transportation and recycling of wastes in the Pars Special Economic Energy Zone, Bushehr. Iran South Med J. 2014; 16:508-518.

23 Abulhasan M, Elshazly TA, Eida M, Albadry A. Giardia intestinalis in patients with nonulcer dyspepsia. Arab J Gastroenterol. 2013; 14:126-129. 